\title{
ON THE CATALYTIC DECOMPOSITION OF HYDROGEN PEROXIDE BY THE CATALASE OF BLOOD
}

\author{
BY ('. A. IOVAT'T EVANS.
}

IFrom the Physiological Laboratory of the Lniversity of Birmingham

(Reccived F̈anumy isth, 1907)

Schönbein ( 1 ) in 1856 called attention to the fact that when extracts of many animal and vegetable tissues were treated with tincture of guaiacum in presence of air, a blue colour was developed. He also showed that the extracts possessed the power of decomposing hydrogen peroxide into water and free oxygen, and believed that both these properties were common to all ferments. Schmidt (2), 1872 , suggested that in the case of blood these two reactions were both due to haemoglobin, and not to the presence of ferments at all.

Jacobson (3), 1892, demonstrated that when the juices of various plants were carefully heated, the power of breaking up hydrogen peroxide very soon vanished, but that the diastatic properties were retained until a much higher temperature had been reached.

Lépinois (4), I 899, suggested that the decomposition of hydrogen peroxide was due to the presence of a definite ferment.

Loew (5), 1900, as the result of extensive investigations, was also led to regard this property as the specific function of a distinct enzyme, to which he gave the appropriate name of Catalase. He classed catalase with the oxydases for various reasons, and distinguished two varieties of catalase, the $\beta$ variety being more readily soluble than the a form.

Many views have been expressed by different writers as to the possible rôle of catalase and its near relatives the oxygenases and peroxydases in the living organism, but this question has not yet received a satisfactory explanation. 
Pozzi-Escot (6), I902, indicated the probable identity of Loew's Catalase with Rey-Pailhade's 'Philothion,' and was the first to study the velocity of the reaction between solutions of blood and hydrogen peroxide. His conclusions were that the amounts of oxygen liberated were proportional to the amounts of enzyme present, and that the velocity of the reaction was a function of the 'active mass.' The same author also studied the effects of some of the substances that exercise a 'poisonous' influence upon catalase. Ville and Moitessier (7) also enquired into the rate at which the decomposition proceeds; their conclusions were, broadly speaking, in agreement with those of Pozzi-Escot, but were not nearly so explicit.

G. Senter (8), 1903, introduced a useful method for isolating the enzyme in a fairly pure condition in solution from defibrinated ox blood. He called the enzyme Haemase, and found that within certain limits a very close approximation to the formula for a reaction of the first order was obtainable when solutions of haemase acted upon dilute solutions of hydrogen peroxide. The effects of various poisons were studied, and the mechanism of their action discussed. Senter and also Neumann Wender (9) showed that the catalytic phenomenon is a function quite distinct from any other enzyme action.

Bach (I0), 1905, in the course of investigations on catalase arrived at the same conclusions as Senter and others with regard to the speed of the decomposition, and proved that the times taken by various amounts of catalase to decompose a given mass of $\mathrm{H}_{2} \mathrm{O}_{2}$ decreased much more rapidly than the amount of enzyme increased.

In the same year Senter (II) published an account of further experiments on the effects of various types of retarding substances on the reaction, and put forth some interesting speculations as to their mode of action upon haemase as compared with inorganic catalysts.

Hans Euler (12), working with the catalase of Boletus scaber, found that within certain limits the velocity of the action of this enzyme on hydrogen peroxide could be expressed by the usual formula for a reaction of the first order.

Quite recently van Laer (13) has studied the catalyses effected 
by ground malt and by yeast, and has shown that there exist optimum concentrations of $\mathrm{H}_{2} \mathrm{O}_{2}$, at which each material is most active in causing evolution of oxygen. He employed an ingenious graphic method for eliminating from the results the loss of catalase which accompanies the progress of the reaction, and is of the opinion that when this correction is made, the law of mass action for a unimolecular reaction is very closely followed.

The purpose of the present investigation is to re-examine the reaction between solutions of catalase and hydrogen peroxide, in the light of recent conceptions of the nature of enzyme action. ${ }^{1}$ It has been clearly shown that on theoretical grounds, a close agreement with the usual formula expressing a reaction of the first order is, where enzyme action is concerned, only possible under certain conditions. The amount of enzyme, for example, should be fairly constant throughout the observation, and the substrate must be dilute.

Moreover, the ratio of enzyme to substrate must not be very small. Even under the very best circumstances the constants at the beginning and end of the reaction frequently deviate a good deal from the mean values. The experiments of A. J. Brown (14), Armstrong (15), and others upon various enzyme actions clearly demonstrate that the laws worked out for inorganic catalysts must be applied with caution to enzymes.

Much uncertainty also exists as to the relation between the concentration and activity of catalase solutions; in fact, nothing very definite seems to have been done in the direction of ascertaining what law this enzyme follows, except within certain narrow limits of concentration.

Preliminary experiments having shown that the reaction was exceedingly susceptible to modification by alterations in the concentration of the hydrogen peroxide, it was thought that by taking this property of catalase into account, some light might possibly be thrown on the questions of the rate of the reaction and relative activity of the enzyme under various conditions.

\footnotetext{
I. For an excellent summary of modern views of enzyme action see the article on that subject by Prof. Benjamin Moore in 'Recent Advances in Physiology and Bio-Chemistry' 1906; pub. Ed. Arnold. 188. net.
} 


\section{Methods}

Many experimental difficulties are encountered in working with animal catalase. For example, when the ratio of enzyme to substrate is small and the concentration of the latter high, there is a rapid cessation of the action. This appears to be due to a poisonous effect of the hydrogen peroxide on the catalase; it can be to a great extent avoided by working at as low a temperature as is convenient ( $10^{\circ} \mathrm{C}$. or under).

The reactions were, therefore, carried out in a thermostat; in some cases the vessels were surrounded with finely broken melting ice instead. The solutions employed were in all cases brought to the required temperature by a prolonged immersion in the thermostat, or in the broken ice.

The hydrogen peroxide solutions were prepared by suitable dilutions of Merck's Perhydrol (30 per cent.) with pure distilled water free from $\mathrm{CO}_{2 .}$.

For the enzyme solution, blood drawn direct from the finger, or freshly defibrinated ox blood were sometimes made use of; the best, however, was found to be the 'Haemase' solution prepared from ox blood according to Senter's method (8). This is free from haemoglobin, and seems to contain no other enzymes beside catalase ; it keeps well if stored in an ice-chest.

Two methods were employed in order to determine the amounts of peroxide catalysed in given periods of time. The first method consisted in the measurement of the volume of oxygen evolved from the reaction mixture, this volume being subsequently corrected for temperature, pressure and tension of aqueous vapour. This method is the one which has been most extensively used for determining the effect of various catalysors on hydrogen peroxide.

In the other method which is due to Senter $(8, \mathrm{II})$, the progressive diminution in the concentration of the substrate was directly measured. Known volumes of the reaction mixture were pipetted off at stated intervals of time, and run into dilute sulphuric acid. The acid instantly stopped the action of the enzyme, and the fluids could 
then be titrated with a standard solution of potassium permanganate of appropriate strength.

The titration method is best used with Senter's 'Haemase' as the source of the enzyme, since the amount of extraneous organic matter in that solution is so small that it is almost negligible : a control titration is nevertheless necessary in order to determine the volume of permanganate solution required to strike a permanent standard pink with a known volume of a blank mixture. This mixture is made by taking water and enzyme in the same proportions as the peroxide and haemase were used in the reaction mixture.

In the experiments on reaction velocity the values of the constant $\mathrm{K}=\frac{\mathrm{I}}{\theta} \log \frac{a}{a-x}$ were calculated in order to ascertain the extent to which the reaction agreed with formula for a monomolecular reaction. (In this formula $\mathrm{K}=0.4343 \mathrm{k}$.)

Senter (8) has employed a somewhat different formula in his calculations; it has the disadvantage of multiplying experimental errors greatly, and does not, moreover, give very different results to the formula generally used. The usual formula has therefore been retained.

In using the first method of measurement a very serious source of error and inconstancy is soon encountered. The reaction mixture becomes supersaturated with oxygen, which is suddenly liberated on the slightest commotion being set up in the liquid.

The following experiment shows the influence of such disturbances on the volumes of oxygen evolved and on the values of $\mathrm{K}$ :-

TABLE I

60 c.c. of $\mathrm{H}_{2} \mathrm{O}_{2}\left(=50\right.$ c.c. available $\left.\mathrm{O}_{2}\right)+5$ c.c. of enzyme solution. Temperature $4^{\circ} \mathrm{C}$.

\begin{tabular}{ccccc}
$\theta$ min. & \multicolumn{4}{c}{$\begin{array}{c}\text { C.c.'s of oxygen } \\
\text { crolved }\end{array}$} \\
I & $\ldots$ & $9 \cdot 8$ & $\ldots$ & $\mathrm{K}$ \\
2 & $\ldots$ & $5 \cdot 2$ & $\ldots$ & 0.0947 \\
$3^{*}$ & $\ldots$ & $7 \cdot 0$ & $\ldots$ & 0.0774 \\
4 & $\ldots$ & $3 \cdot 4$ & $\ldots$ & 0.0770 \\
5 & $\ldots$ & $2 \cdot 8$ & $\ldots$ & $0.072 \mathrm{I}$ \\
6 & $\ldots$ & $2 \cdot 8$ & $\ldots$ & 0.0700 \\
$7^{*}$ & $\ldots$ & $4 \cdot 4$ & $\ldots$ & 0.0760 \\
8 & $\ldots$ & $1 \cdot 2$ & $\ldots$ & 0.0715 \\
9 & $\ldots$ & $1 \cdot 0$ & $\ldots$ & 0.0673 \\
10 & $\ldots$ & 0.9 & $\ldots$ & 0.0639
\end{tabular}


The contents of the flask were shaken at the commencement of the periods marked by asterisks, i.e., at the beginning of the third and seventh minutes. The increase in the volume of oxygen evolved is well seen.

The process of saturation of the mixture with oxygen is, however, by no means so rapid as might be imagined. Hence the volumes of gas evolved in equal intervals of time during the early stages of the reaction increase until a maximum volume is attained. This point is best brought out when moderate concentrations of $\mathrm{H}_{2} \mathrm{O}_{2}$ are employed; the table given below is a good example of the phenomenon.

TABLE II

$$
200 \text { c.c. } \frac{\mathrm{N}}{5} \mathrm{H}_{2} \mathrm{O}_{2}+\begin{array}{ccc}
\text { Io c.c. dilute enzyme solution. Temperature } 4^{\circ} \mathrm{C} \text {. } \\
\theta \text { min. } & \multicolumn{3}{c}{\text { C.c.'s' of oxygen evolved }} \\
3 & \ldots & 795 \\
6 & \ldots & 12 \cdot 85 \\
9 & \ldots & 19 \cdot 9 \\
12 & \cdots & 16 \cdot 3
\end{array}
$$

The time necessary for the tension of the oxygen in the solution to reach its maximum is in this case between nine and twelve minutes.

There can be no doubt that by the use of appropriate stirring gear these physical defects might be greatly reduced; at the same time it is questionable whether the supersaturation error could ever be entirely removed in this way.

Notwithstanding these somewhat serious fallacies the method was frequently made use of since there are details in its favour.

There do not seem to be any marked sources of error attending the use of the titration method when the experiment is properly carried out.

\section{Influence of Varying Concentrations of Hydrogen Peroxide}

When, in a series of estimations, the relative amount of catalysis effected by equal amounts of enzyme solutions of the same strength acting upon equal volumes of hydrogen peroxide of various concentrations are studied, it is found that the rate of decomposition increases 
CATALYTIC DECOMPOSITION OF HYDROGEN PEROXIDE I 39

with increasing concentration of $\mathrm{H}_{2} \mathrm{O}_{2}$, up to a certain point beyond which it again falls off rapidly.

In the experiment given below the rate of catalysis was measured by the collection method, the volume of oxygen being measured in each observation at the end of five, ten and fifteen minutes. The concentration of the peroxide ranged from 30 per cent. to $0^{\circ} 04$ per cent. (by weight).

TABLE III

$$
\begin{aligned}
& \text { Io c.c. } \mathrm{H}_{2} \mathrm{O}_{2}+\text { I c.c. strong enzyme. Temperature } 15^{\circ} \mathrm{C} \text {. } \\
& \text { Time Concentration of hydrogen peroxide }
\end{aligned}
$$

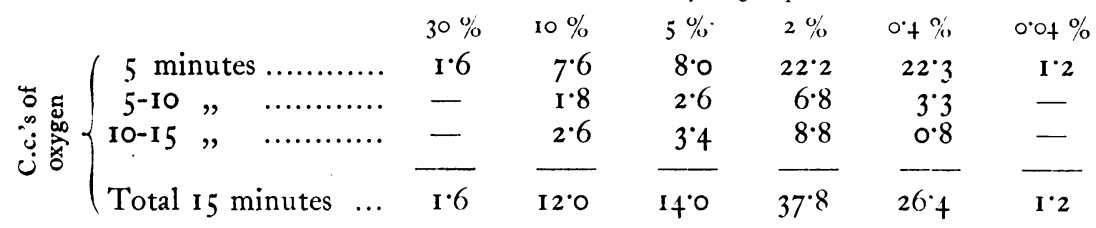

There is very little difference between the volumes of gas evolved from 30 per cent. and $0^{\circ} 04$ per cent. solutions. The maximum activity was somewhere between $0^{\circ} 4$ per cent. and $2^{\circ} \circ$ per cent.

It is interesting to notice that at several of the concentrations the oxygen liberated during the third period of five minutes is considerably greater than that evolved during the second interval. This phenomenon is always more or less marked when the same method is employed, though the difference may not always be obvious when periods as long as five minutes are under observation: it appears to be due to the fact that the mixture slowly becomes supersaturated with oxygen. During the first five minutes there is a considerable bulk of oxygen evolved; the commotion caused by its brisk liberation is, however, so considerable that very little supersaturation is likely to occur until after the effervescence has in some degree subsided. The reaction mixture would then slowly supersaturate with oxygen, as in the experiment of Table No. II, with the result that the volume of gas evolved during the second interval would be less than that given off during the third.

That this explanation is at least partly correct may be shown by comparing the volume of oxygen evolved with the volume actually resulting from the decomposition as measured by the titration method. 
The following table gives the results of two parallel experiments by the two methods :-

\section{TABLE IV}

C.c.'s of oxygen at N.T.P. from 5 c.c. $\mathrm{H}_{2} \mathrm{O}_{2}$ and $\frac{1}{2}$ c.c. enzyme solution Temperature $10^{\circ} \mathrm{C}$.

\begin{tabular}{|c|c|c|c|c|c|}
\hline & \multicolumn{2}{|c|}{$\mathrm{H}_{2} \mathrm{O}_{2}$ at $2.68 \%$} & \multicolumn{2}{|c|}{$\mathrm{H}_{2} \mathrm{O}_{2}$ at $5.72 \%$} \\
\hline & & $\begin{array}{l}\text { Evolved and } \\
\text { measured }\end{array}$ & $\begin{array}{l}\text { Found by } \\
\text { titration }\end{array}$ & $\begin{array}{l}\text { Evolved and } \\
\text { measured }\end{array}$ & $\begin{array}{l}\text { Found by } \\
\text { titration }\end{array}$ \\
\hline 5 minutes & .... & II I 90 & $29^{\circ} 00$ & 6.05 & $14 \cdot 30$ \\
\hline 5-10, & $\ldots \ldots \ldots$ & $5^{\circ} 97$ & II 50 & 3.48 & 347 \\
\hline $10-15 \%$ & ......... & $8 \cdot 72$ & 3.07 & 495 & I. I 8 \\
\hline & & $26 \cdot 59$ & 4355 & $14 \cdot 48$ & $18 \cdot 95$ \\
\hline
\end{tabular}

The amounts of oxygen formed by the decomposition are seen to progressively diminish as the reaction proceeds, whilst those evolved and collected show the variation referred to above. In the case of the weaker hydrogen peroxide the amount of oxygen still retained in the fluid is 16.98 c.c., and in the 5.72 per cent. peroxide 4.47 c.c.

The question that naturally suggested itself after the foregoing experiments was whether the optimum point in the concentration of the $\mathrm{H}_{2} \mathrm{O}_{2}$ varied with the strength of the catalase solution, and if so, to what extent.

In order to decide this point, solutions of laked blood of various dilutions were employed, and the maximum found for each concentration used. The results of a preliminary experiment are given below :-

\section{TABLE V}

5 c.c. $\mathrm{H}_{2} \mathrm{O}_{2}$ solution +0.5 c.c. diluted blood

\begin{tabular}{|c|c|c|c|c|c|c|c|c|}
\hline & & & & $\mathrm{H}_{2} \mathrm{O}$ & & & & \\
\hline & & & $5 \%$ & $4 \%$ & $3 \%$ & $2 \%$ & I \% & $0.5 \%$ \\
\hline & 5 minutes & $\ldots$ & $7 \cdot 2$ & $9^{\circ} \mathrm{I}$ & 20.7 & $2 \mathrm{I} \cdot 2$ & $19^{\circ} 0$ & 8.9 \\
\hline & 5-10, & $\ldots$ & $3 \cdot 2$ & $7 \cdot 1$ & 79 & $13 \cdot 6$ & $I \cdot 2$ & 14 \\
\hline & $10-15$ & $\ldots$ & 43 & $7 \cdot 6$ & $7 \cdot 3$ & $5 \cdot 4$ & 0.4 & 0.6 \\
\hline & Tatal & $\ldots$. & 1.77 & $23 \cdot 8$ & 359 & $40^{\circ} 2$ & $20 \cdot 6$ & $10^{\circ} 9$ \\
\hline
\end{tabular}

The maximum liberation of gas occurs when the percentage of $\mathrm{H}_{2} \mathrm{O}_{2}$ lies between 2 per cent. andi 3 per cent. 


\section{CATALYTIC DECOMPOSITION OF HYDROGEN PEROXIDE I4I}

TABLE Va

5 c.c. $\mathrm{H}_{2} \mathrm{O}_{2}$ solution +0.5 c.c. diluted blood (half strength of above)

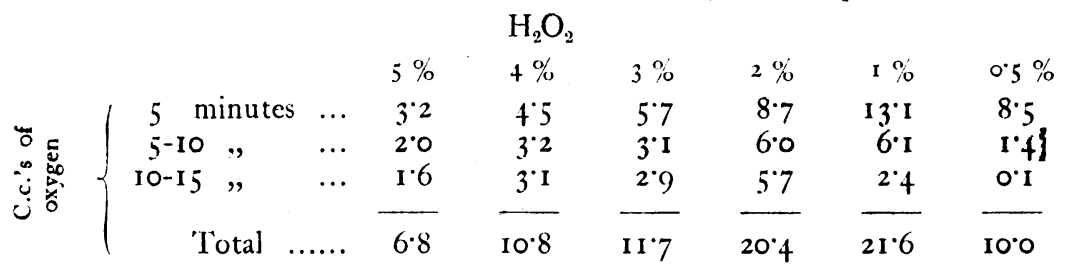

Maximum liberation between I per cent. and 2 per cent. of $\mathrm{H}_{2} \mathrm{O}_{2}$.

TABLE $\mathrm{Vb}$

5 c.c. $\mathrm{H}_{2} \mathrm{O}_{2}$ solution +0.5 c.c. diluted blood (one-quarter strength of that used in $\mathrm{V}$ )

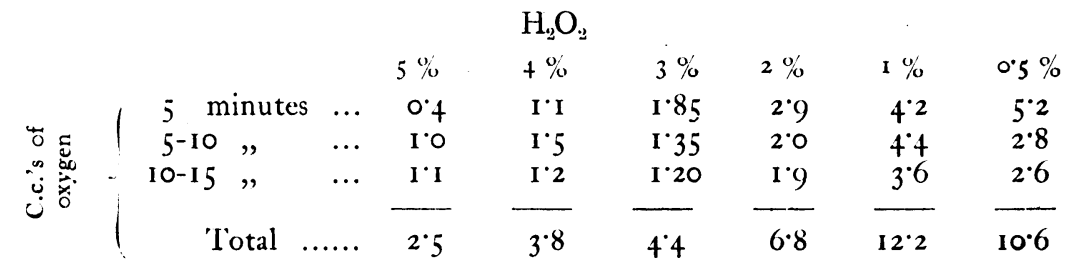

Maximum liberation at $0.5-\mathrm{I}$ per cent. $\mathrm{H}_{2} \mathrm{O}_{2}$.

It is evident from a consideration of these results that the optimum concentration of the substrate does vary with the amount of enzyme used.

It might be supposed that in the above experiment the optimum for the strongest blood solution was $2 \frac{1}{2}$ per cent. of $\mathrm{H}_{2} \mathrm{O}_{2}$, in the second series $\mathrm{I}_{4}$ per cent., and in the case of the weakest solution about 0.63 per cent.-i.e., that the optimum concentration of $\mathrm{H}_{2} \mathrm{O}_{2}$ varies directly as the concentration of the enzyme.

The following experiment, however, shows that this is not the case; in this observation a stronger solution of blood was used in the first instance in order to raise the optima somewhat throughout.

$$
\begin{aligned}
& \text { Table VI } \\
& \mathrm{H}_{2} \mathrm{O}_{2} 5 \text { c.c. Blood solution } 0.5 \text { c.c. } \\
& \mathrm{H}_{2} \mathrm{O}_{2} \\
& \begin{array}{llllllllll}
\text { Dilution of blood solution } \quad 5 \% & 4 \% & 3 \% & 2 \cdot 5 \% & 2 \% & 1 \cdot 75 \% & 1 \cdot 5 \% & 1.25 & 1 & 1 \cdot 0 \%
\end{array}
\end{aligned}
$$

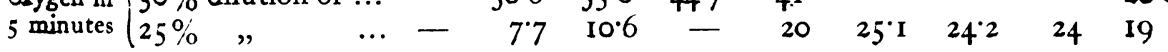

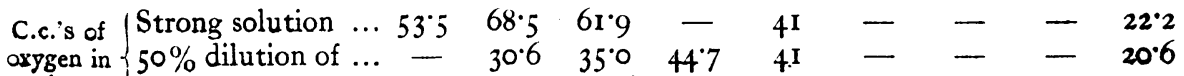

(It was found that equally comparable results were obtained by measuring the gas evolved during the first five minutes as by measuring that liberated in fifteen minutes.) 
The maxima in these three series were :-

11 ith strong enzyme between 3 per cent. and + per cent. $\mathrm{H}_{2} \mathrm{O}_{2}$ (mean 35 ).

,$\quad 50$ per cent. of enzyme between 2 per cent. and 2.5 per cent. $\mathrm{H}_{2} \mathrm{O}_{2}$ (mean 2.25 ).

" 25 per cent. of enzyme between $\mathrm{I}^{\prime} 5$ and $\mathrm{I}^{\prime} 75$ per cent. $\mathrm{H}_{2} \mathrm{O}_{2}$ (mean $\mathrm{I}^{\circ} 62$ ).

The optimum percentage concentrations of $\mathrm{H}_{2} \mathrm{O}_{2}(\omega)$, therefore, do not vary directly as the concentrations of the enzyme (e) but more nearly as their square roots :-

T'AbLe VIa

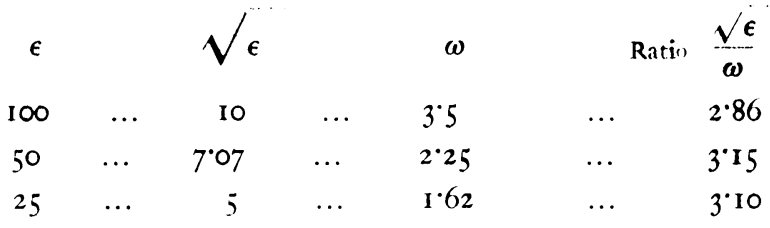

It would, however, be far from wise to express this as a definite law, for the reason that in all probability a different relation would be established when very wide ranges in concentration of catalase were examined. All that can be said is that for the strengths obtained by ordinary dilutions of blood this rule seems to hold approximately.

\section{Influence of Varying Concentrations of Enzymes}

If any law connects the activity of solutions of catalase with their concentration, it is certainly somewhat obscure; no rule seems to be clearly followed at any very wide limits of concentration.

Theoretically, catalase lends itself admirably to the solution of such a problem, since it is easy to observe the times necessary for equal amounts of change, when a constant volume of enzyme solution of different strengths acts on a uniform amount of hydrogen peroxide solution of a fixed percentage concentration. Moreover the end products, oxygen and water, from their nature cannot accumulate and interfere with the reaction, especially when only an early stage of the latter is studied. These conditions would appear to be almost ideal, and the relative activity of any two solutions of catalase would, as indicated by B. Moore (I6), be inversely proportional to the times necessary for the evolution of equal volumes of oxygen. 
Quite an unexpected factor is introduced, however, by the great difference in the influence of hydrogen peroxide solutions in inducing destruction of catalase when present in varying amounts in the solution ; generally speaking the weaker the enzyme the more readily it is destroyed by the substrate. It was eventually found that different laws were followed at different ranges of strength of catalase. These it is believed may be to a large extent explained on taking into account two properties of catalase already mentioned, viz: -

I. That there are optimum concentrations of hydrogen peroxide which are different for each new strength of enzyme employed.

II. That when the relative amount of substrate is large, catalase is rapidly changed into an inactive form.

In the experiment given in tabular form below, laked blood was used as the source of the enzyme. The activities of the various admixtures of blood and water were compared by observing the times necessary for the liberation of 10 c.c. of oxygen when the enzyme solution acted on I per cent. hydrogen peroxide. After making the necessary calculations it was possible to compare activity with concentration of enzyme.

\begin{tabular}{|c|c|c|c|c|}
\hline \multicolumn{5}{|c|}{$\begin{array}{c}\text { TABLE VII } \\
\text { I per cent. } \mathrm{H}_{3} \mathrm{O}_{2} 50 \text { c.c. }+ \text { IO c.c. blood solution }\end{array}$} \\
\hline $\begin{array}{c}\text { Relative } \\
\text { concentration } \\
\text { of enzyme } \\
{[\epsilon]}\end{array}$ & & $\begin{array}{c}\text { Time in scconds } \\
\text { to evolve to c.c. } \\
\text { oxygen } \\
{[\mathrm{t}]}\end{array}$ & & $\begin{array}{l}\text { Relative activity } \\
(a) \\
{\left[=\frac{2 \cdot 3}{t} \times 100\right]}\end{array}$ \\
\hline 100 & $\ldots$ & $2 \cdot 3$ & $\ldots$ & 100 \\
\hline 50 & $\ldots$ & $3 \cdot 0$ & $\ldots$ & $76 \cdot 7$ \\
\hline 40 & $\ldots$ & 3.6 & $\ldots$ & $63 \cdot 8$ \\
\hline 30 & $\ldots$ & $4^{\circ} \circ$ & $\ldots$ & $57^{\circ} 4$ \\
\hline 20 & $\ldots$ & 577 & $\ldots$ & $40 \cdot 3$ \\
\hline 15 & $\ldots$ & $7 \cdot 0$ & $\ldots$ & $32 \cdot 7$ \\
\hline 10 & $\ldots$ & $10 \cdot 2$ & $\ldots$ & $22 \cdot 6$ \\
\hline 6 & $\ldots$ & 13.8 & $\ldots$ & $16 \cdot 6$ \\
\hline 4 & $\ldots$ & 24.2 & $\ldots$ & 9.5 \\
\hline 2 & & $65 \cdot 2$ & $\ldots$ & 3.52 \\
\hline I & $\ldots$ & $212: 8$ & $\ldots$ & 1.08 \\
\hline 0.2 & $\ldots$ & $1841^{\circ} 0$ & $\ldots$ & 0.125 \\
\hline
\end{tabular}


It would at first seem as though nothing approaching a fixed rule is followed here, and on attempting to analyse the graphic curve relating concentration and activity it was indeed found that no simple mathematical expression could be found to represent the relation.

On closer examination, however, it was found possible to divide the enzyme concentrations into three ranges, for two of which separate formulae were approximately correct.

When we consider the results for enzyme solutions the relative strengths of which range between 100 and 30 in the above table, we see that Schütz's law, which is said to apply for wide limits of concentration in the use of a large number of enzymes, is fairly well adhered to in this case also. The table given below illustrates this :-

\begin{tabular}{|c|c|c|c|c|}
\hline \multirow{3}{*}{$\begin{array}{c}\text { Linzyme } \\
\epsilon\end{array}$} & \multicolumn{3}{|c|}{ I'ABLE VIIa } & \multirow{2}{*}{$\underset{a}{\text { Ratio }}$} \\
\hline & & Activit & & \\
\hline & & $a$ & & $\frac{a}{\sqrt{\epsilon}}$ \\
\hline 100 & $\ldots$ & 100 & $\ldots$ & $10^{\circ} 0$ \\
\hline 50 & $\ldots$ & $76 \cdot 7$ & $\ldots$ & 10.8 \\
\hline 40 & $\ldots$ & $63 \cdot 8$ & $\ldots$ & $10 \% 06$ \\
\hline 30 & $\ldots$ & $57+$ & $\ldots$ & $10 \cdot 50$ \\
\hline
\end{tabular}

When, on the other hand, the relative concentrations lay between thirty and four, that is to say, over the widest range of concentrations studied, the activity varied directly as the concentration. This, it may be remarked, is the usual rule followed by inorganic catalysts such as platinum sol.

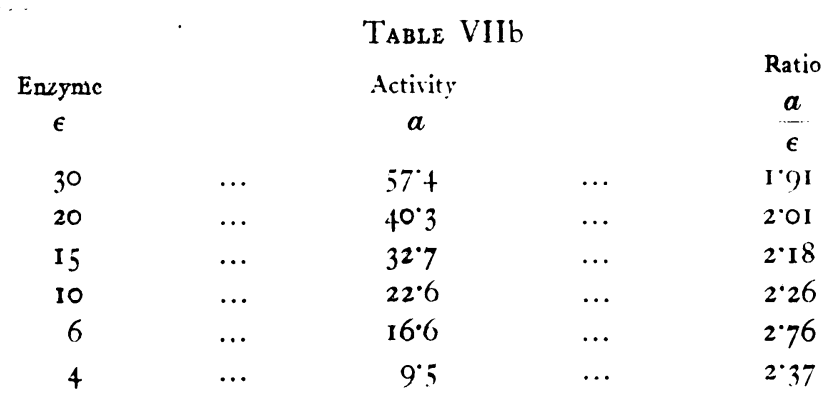

Below four the activities rapidly diminish with lessening concentration of enzyme, and no law is followed over any considerable range of concentrations. 


\section{CATALYTIC DECOMPOSITION OF HYDROGEN PEROXIDE 145}

These results show what has been already abundantly demonstrated, namely, that considerable caution is to be observed when comparing enzymes with inorganic catalysts (the so-called inorganic ferments). The enzyme molecules from their necessarily great complexity are far more liable to be interfered with by any unusual conditions. It seems not at all unlikely that other enzymes may be found to deviate from the usually expressed laws that relate concentration and activity, if very wide limits were studied. Thus Bayliss (17) has shown that trypsin in dilute solutions exhibits a linear law and not the Schütz law which it is said to follow in more concentrated solutions.

In the case of catalase, (and particularly the catalase of animal origin), this body is so extremely susceptible to disturbing influences that the ranges over which any law holds are necessarily very narrow. We may assume that in the absence of the two interfering factors previously mentioned, the catalysor would follow the law which usually applies to inorganic catalysts, viz., that the activity of the enzyme solution is directly proportional to its concentration.

These interfering factors were at a minimum when the enzyme concentration lay between the numbers thirty and four (the peroxide being in a I per cent. solution), and this rule was therefore adhered to over this range.

For stronger solutions of blood, however, the conditions gradually alter, for now the hydrogen peroxide is much below optimum strength, so that the increasing concentrations of enzyme are working at a rapidly increasing disadvantage, as previously shown (Tables VI and VIa). Indeed a point is very soon attained beyond which further increase in the amount of enzyme in solution gives no further activity when measured by the same strength of hydrogen peroxide ( 1 per cent.). Hence, until this maximum point is reached, though the absolute activity increases with the growing concentration of the enzyme, the relative catalysing power diminishes. The Schütz law is an empirical way of expressing this fact.

Below the relative concentration six in Table VII, another disturbing factor comes into play. The amount of enzyme is now so. 
small that the substrate is a supra-optimal one ; the catalase accordingly suffers alteration to a rapidly increasing extent with increasing dilution, so that the activity speedily diminishes.

\section{The Velocity of the Reaction \\ The Linear Period}

There is abundant evidence that during the early stages in the action of many enzymes there is a period, the duration of which depends upon various conditions, during which the masses of substrate converted in equal intervals of time are approximately equal, i.e., there is a distinct tendency for the conversion of a constant mass of the substance undergoing disintegration, and not of a constant fraction of it. Thus A. J. Brown (18) working with invertase, Armstrong (19) with various sucroclastic enzymes, and Bayliss (20) with trypsin, have found that when the amount of enzyme present is relatively small, the values of the constant $\mathrm{K}=\frac{\mathrm{I}}{\theta} \log \frac{a}{a-x}$. steadily increase during the earlier phases of the reaction.

Armstrong (2I) has even shown that the sucroclastic action of dilute acids may follow the same course.

Previous investigators have all come to the conclusion that the decomposition of hydrogen peroxide by catalase very closely resembles its breaking down by inorganic catalysts. This is undoubtedly true for the strength of peroxide usually employed, which has generally been diluted to such an extent that the ratio of substrate to enzyme would not be very considerable. Under these conditions the progress of the reaction is such as may be expressed by the usual empirical formula for a monomolecular decomposition.

As might be anticipated the linear period is best shown when the ratio of peroxide to catalase is as large as it can be made without interfering with the action of the latter to any considerable extent; that it is of great importance that the peroxide be not too concentrated will be evident on recalling the results already submitted (Table III).

The figures in Table VIII are from an experiment in which the 'collection' method was used: the flask containing the reacting substances was surrounded by ice. 


\begin{tabular}{ccc}
\multicolumn{4}{c}{ Table VIII } \\
200 c.c. $\mathrm{H}_{2} \mathrm{O}_{2}$ & $\mathrm{~N} / 5.68$ & + ro c.c. dilute enzyme solution \\
'Time & C.c.'s of oxygen & $\mathrm{K}=\frac{1}{\theta} \log \frac{a}{a-x}$ \\
$\theta$ & (corrected) & 0.00600 \\
3 & $7 \cdot 95$ & 0.00808 \\
6 & 12.85 & 0.0111 \\
9 & 19.90 & 0.0123 \\
12 & 16.30 & 0.0126 \\
15 & $12 \cdot 70$ & 0.0130 \\
18 & 12.50 & 0.0120 \\
24 & 13.60 &
\end{tabular}

Here we have a progressive rise in the value of $\mathrm{K}$, which increases for eighteen minutes. The method used has, however, been shown to be open to serious fallacies; these results are given merely to show that the linear period may be rendered evident by this method, which is the one that had been most extensively used until Senter introduced the titration method.

Even after the expiration of the nine or twelve minutes necessary for complete saturation of the solution with oxygen, there is still a distinct tendency for the reaction to remain linear. Thus in the two successive periods ending at the fifteenth and eighteenth minutes practically equal volumes of oxygen are evolved, pointing to the conversion of a nearly constant mass of substrate in each of the two intervals of time.

The next two experiments were performed by the titration method, which is not liable to the errors attendant upon the older method.

\section{TABLE IX}

50 c.c. $\mathrm{N} / 50 \mathrm{H}_{2} \mathrm{O}_{2}+50$ c.c. extremely dilute enzyme. Temperature $20^{\circ} \mathrm{C}$.

Io c.c. of reaction mixture titrated at stated intervals with approximately $\mathrm{N} / 500 \mathrm{KMnO}_{4}$ solution.

$\begin{array}{ccc}\theta \text { (min.) } & \mathrm{C}^{2} \mathrm{H}_{2} \mathrm{O}_{2} & \mathrm{~K} \\ 0 & 40.90 & - \\ 5 & 16.40 & .0794 \\ 10 & 5.70 & .0856 \\ 15 & 2.05 & .0866 \\ 20 & 0.90 & .0829 \\ 30 & 0.55 & .0624\end{array}$


TABLE $X$

100 c.c. $\mathrm{N} / 100 \mathrm{H}_{2} \mathrm{O}_{2}+100$ c.c. of enzyme solution (strength one-half of that used in previous experiments). Temperature $20^{\circ} \mathrm{C}$.

$\begin{array}{clr}\theta(\min ) & \mathrm{C} / \mathrm{H}_{2} \mathrm{O}_{2} & \mathrm{~K} \\ 0 & 55.35 & - \\ 5 & 45.25 & .0175 \\ 10 & 35.80 & .0189 \\ 20 & 23.50 & .0186 \\ 30 & 15.85 & .018 \mathrm{I} \\ \text { to } & \mathrm{II} \cdot 10 & .0174\end{array}$

In both experiments an increase in the values of $\mathrm{K}$ is noticeable early in the reaction. The rise is much more marked in the observation in which both solutions were more concentrated, in fact the second series of figures might be said to show a very fair agreement with the requirements for a monomolecular reaction.

Only one more result need be quoted.

In the following experiment the ratio of substrate was very great, and when the observation was carried out at a temperature of $20^{\circ} \mathrm{C}$. the values of $\mathrm{K}$ rapidly fell off from the very commencement, but at $10^{\circ} \mathrm{C}$. the figures below were obtained.

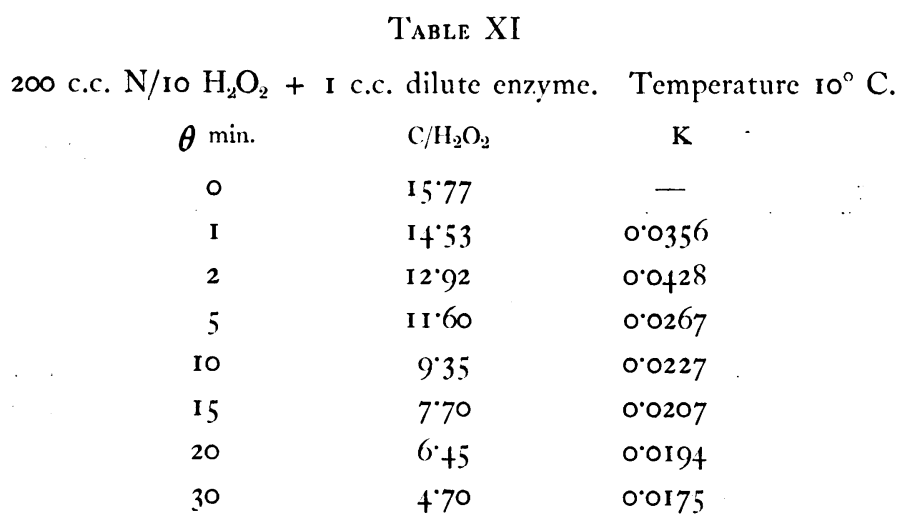

The increase in the value of the constant very rapidly ceased, even under fairly favourable conditions. Parallel experiments gave the same results, so that there can be no doubt that the constant did actually rise. 


\section{CATALYTIC DECOMPOSITION OF HYDROGEN PEROXIDE I49}

When the amount of peroxide was still further increased, and especially if the temperature was not very low, the velocity rapidly fell off right from the commencement of the action. Tables XII and XIII illustrate this.

TABLE XII

25 c.c. $\mathrm{N} / \mathrm{ro}_{2} \mathrm{O}_{2}+5$ c.c. extremely dilute enzyme. Temperature $14^{\circ} \mathrm{C}$.

$\begin{array}{llc}\theta \text { min. } & \mathrm{C} / \mathrm{H}_{2} \mathrm{O}_{2} & \mathrm{~K} \\ 0 & 34 \cdot \mathrm{I} & - \\ 0.25 & 33 \cdot \mathrm{I} & 0.05 \mathrm{I} 7 \\ 0.5 & 32 \cdot 9 & 0.03 \mathrm{II} \\ 0.75 & 32 \cdot 6 & 0.0260 \\ \mathrm{I} \cdot 0 & 32 \cdot 25 & 0.0242 \\ \mathrm{I} \cdot 5 & 31 \cdot 5 & 0.0230\end{array}$

TABLE XIII

250 c.c. $\mathrm{N} / 10 \mathrm{H}_{2} \mathrm{O}_{2}+5$ c.c. extremely dilute enzyme. Temperature $20^{\circ} \mathrm{C}$.

$\begin{array}{rcc}\theta \text { min. } & \mathrm{C} / \mathrm{H}_{2} \mathrm{O}_{2} & \mathrm{~K} \\ 0 & 25 \cdot 70 & - \\ \mathrm{I} & 24 \cdot 80 & 0.0155 \\ 3 & 23.80 & 0.01 \mathrm{II} \\ 5 & 22.65 & 0.0109 \\ 10 & 21 \cdot 70 & 0.0073 \\ 15 & 21.00 & 0.0058 \\ 20 & 20.45 & 0.0050 \\ 30 & 19.75 & 0.0038 \\ 40 & 18.70 & 0.0034\end{array}$

It was thought that further demonstration of the linear period could be furnished by comparing the times necessary for equal initial amounts of catalase to produce equal small amounts of change in solutions of hydrogen peroxide of varying concentration. If there is a tendency for the conversion of a constant mass the times should tend to be equal over a fairly wide range of concentration of peroxide. On the other hand, supposing that a constant fraction is converted in unit time, then the times would vary very much, e.g., a certain amount of change wrought in a 3 per cent. solution in say four minutes, would require about $9^{\cdot} \mathrm{I}$ minutes for its completion when a $I_{\frac{1}{2}}$ per cent. solution of hydrogen peroxide was employed.

The following experiment is an example of the results obtained. 


\section{TABLE XIV}

Io c.c. $\mathrm{H}_{2} \mathrm{O}_{2}+$ I c.c. dilute laked blood. Temperature $3^{\circ} \mathrm{C}$.

$$
\mathrm{H}_{2} \mathrm{O}_{2} \%
$$

$\begin{array}{llcccccccc}\text { Percentage of } \mathrm{H}_{2} \mathrm{O}_{2} & \text { 10 } & 5 & 3 & 2 \frac{1}{2} & 2 & 1 \frac{1}{2} & \text { I } & \frac{3}{4} & \frac{1}{2} \\ \begin{array}{c}\text { Time in min. to evolve } \\ \text { Io c.c. oxygen }\end{array} & 8 & 6 \cdot 10 & 2 \cdot 20 & 2 \cdot 30 & 2 \cdot 31 & 2 \cdot 50 & 2 \cdot 55 & 3 \cdot 20 & 4 \cdot 30\end{array}$

The optimum concentration is apparently at about 3 per cent. Between 3 per cent. and I per cent. the times are very nearly uniform, much more so than could have been the case had the usual law of mass action been closely followed.

These results can leave no doubt as to the existence of a linear period early in the course of the decomposition. The initial velocity is, however, very soon diminished, especially when strong solutions of hydrogen peroxide are employed. There are strong grounds for believing that the effect of a high proportion of substrate is to induce a change in the catalase molecule, whereby the latter is rendered unfit for carrying on further catalysis. This transformation of the enzyme into an inert form is generally said to be due to a combination of the enzyme with the oxygen set free by the decomposition; if so, then the union must occur either when the oxygen is yet in a nascent condition, or subsequently as a result of the accumulation of the free gas.

The latter alternative may be dismissed, seeing that when supraoptimal concentrations of the substrate are used very little oxygen is evolved at any stage of the reaction.

Nor does the former hypothesis seem more pregnant since according to Schaffer (22) the oxygen is liberated in a molecular condition and is incapable of bringing about oxidations. (This very important point, however, needs re-investigation).

It would therefore seem as though the only probability is that the peroxide itself exerted some chemical action upon the enzyme.

Speculations as to the nature of this influence are perhaps rather premature, but two possibilities suggest themselves.

In the first place, a solution of hydrogen peroxide, even when quite pure, exhibits many of the properties of an acid. It has been 


\section{CATALYTIC DECOMPOSITION OF HYDROGEN PEROXIDE I5I}

abundantly proved by Senter (23) that solutions of acids and of substances possessing oxidising properties cause a depression of the catalysis by haemase quite apart from any oxidising effect which these substances may produce. When we consider that hydrogen peroxide is a substance which belongs to both classes, we might reasonably suppose that when employed in large excess it might interfere with the steady progress of the reaction. It is also a significant fact that alkalies greatly accelerate the velocity of the change. The other possibility is that the catalase is oxidised by the nascent oxygen set free by the spontaneous decomposition of the hydrogen peroxide. This undoubtedly occurs normally in any unacidified solution of the substance, and may be potent in bringing about destruction of the specific properties of catalase.

\section{The Logarithmic Period}

When a due proportionality is established between substrate and enzyme, whether this be after the persistence of the linear period for some time, or whether the necessary conditions exist at the moment of mixing the two solutions, the law of mass action is followed. The values of $\mathrm{K}$ are now constant. The logarithmic phase is well seen when the substrate used is in very dilute solution and the amount of enzyme not very small.

In the following experiment (Table $\mathrm{XV}$ ) the values of $\mathrm{K}$ are practically constant for fifteen minutes, and it would seem as though the reaction was indeed a true monomolecular one.

\section{TABLE XV}

400 c.c. $\mathrm{N} / 100 \mathrm{H}_{2} \mathrm{O}_{2}+200$ c.c. dilute enzyme (ice thermostat)

$\begin{array}{ccc}\theta \text { (min.) } & \mathrm{C} / \mathrm{H}_{2} \mathrm{O}_{2} & \mathrm{~K} \\ 0 & 10.35 & - \\ \mathrm{I} & 9.32 & 0.0455 \\ 2 & 8.45 & 0.0440 \\ 3 & 7.65 & 0.0438 \\ 4 & 6.90 & 0.0440 \\ 5 & 6.20 & 0.0445 \\ 10 & 4.05 & 0.0407 \\ 15 & 2.55 & 0.0406 \\ . & & \text { Mean }=0.0433\end{array}$




\section{The Period of Marked Slackening}

As a result of the progressive destruction of the catalase, the logarithmic course of the reaction becomes modified and depressed so that the values of $\mathrm{K}$ fall. If the slowing factor is very powerful the first two portions, the linear and logarithmic, are omitted, and the velocity rapidly falls from the very commencement (vide Tables XII and XIII). Under any circumstances this phase will become conspicuous sooner or later, and that it is due to, or at least accompanies, extensive destruction of catalase may be shown according to the method of v. Laer (loc. cit.). After the lapse of twenty-four minutes in the experiment given in Table VIII the original concentration of the substrate was restored by the addition of an amount of 30 per cent. $\mathrm{H}_{2} \mathrm{O}_{2}$, which was equivalent to the oxygen given off. The volumes of oxygen evolved under the new conditions were measured and compared with those given off after the same intervals of time in the first series of readings. The result is given below.

\begin{tabular}{cccc}
\multicolumn{4}{c}{ TABLE XVI } \\
Time & $\begin{array}{c}\text { Reading in } \\
\text { 1st series }\end{array}$ & $\begin{array}{c}\text { Reading in } \\
\text { 2nd series }\end{array}$ & $\begin{array}{c}\text { Ratio }= \\
\text { residual catalase }\end{array}$ \\
9 min. & 40.7 & 23.2 & 0.57 \\
$12 \#$ & 57.0 & 30.3 & 0.53 \\
18 & 82.2 & 39.3 & 0.47
\end{tabular}

The amount of catalase has been reduced to one-half by the end of twenty-four minutes only, showing that animal catalase is very readily destroyed.

Van Laer has, by the application of a method of graphic analysis, eliminated this variability from the results and substituted a number which represents an average amount of catalase throughout the reaction. By this method he has shown that the net result of an action proceeding for 140 minutes is in accordance with the requirements of the law of mass action. This result, however, gives the net result merely, and cannot tell us anything about the fluctuations which the velocity suffers from time to time. Indeed v. Laer's own experiments certainly show the three periods in the reaction admirably, since the yeast catalase is well adapted to long observations. 


\section{Conclusions}

The results of the author's experiments on the reaction velocity of hydrogen peroxide catalysis may, it is believed, be explained by the hypothesis first suggested by Professor Adrian Brown, and subsequently by Armstrong, and now generally known as the 'active system' theory. In the presence of a large excess of substrate the magnitude of the active system would be constant and the reaction rectilinear. At a later stage the formation of active systems would be a function of the total mass of substrate, and hence the curve representing the reaction would be logarithmic.

There is little doubt, however, that an apparently logarithmic course is developed earlier than should be the case very frequently on account of the destruction of a certain amount of the catalase during the first stages of the reaction; for this same reason also the logarithmic period is by no means well sustained, since with a diminishing amount of enzyme the magnitude of the active system will, as Armstrong has shown, be a function of both substrate and enzyme. For this reason the value of $\mathrm{K}$ will fall wherever there is extensive removal of the ferment. Whether there is an equilibrium point in the reaction, and whether the action is or is not reversible, it is difficult at present to determine. There certainly seems to be a balanced point, but this is very near to zero, and the existence of any reversibility factor is very doubtful owing to the gaseous nature of the principal end product. Comparative experiments carried out in atmospheres of oxygen under varying pressures certainly indicate a slight slowing of the reaction when the oxygen tension in the apparatus is considerably increased, but nothing very definite has yet been proved in this direction, chiefly on account of experimental difficulties.

\section{Summary of Results}

I. The two methods in general use are compared, and the fallacies of one of them demonstrated.

2. For each concentration of enzyme there is an 'optimum' 
concentration of hydrogen peroxide. The optima do not vary directly as the enzyme concentrations, but more nearly as their square roots.

3. No single law expresses the relation between the concentration and activity of the enzyme solutions. Above a certain point increase in the strength of the catalase solution is without effect. For some distance from this point the Schütz law is followed. With increasing dilutions of ferment there is a linear relation between the strength of the enzyme solution and the amount of catalysis it can induce. With very great dilutions there is a rapid and irregular departure from this rule. These results are briefly discussed.

4. The velocity with which the catalysis occurs is studied; the three periods common to many enzymatic actions are found to be present. These periods are (a) the Rectilinear, (b) the Logarithmic, (c) the infra-Logarithmic period.

5. These results are explained with the aid of the usual hypothesis of an 'active system,' and the possibility of the action being reversible are very briefly indicated.

In conclusion, I would tender my very hearty thanks to Professor Carlier for his kindly support and direction during the progress of this research, and to Professor Adrian J. Brown for the many valuable suggestions which he was good enough to offer. 


\section{REFERENCES}

(1) Schönbein, F. f. Prakt. Cb. 67 (1856), 496; 89 (1863), 334 .

(2) Schmidt, Pflüger's Arch. 6 (1872), 413.

(3) Jacobson, Z. f. Physiol. Cb. (1892), 340.

(4) Lépinois, Soc. biol., 27 mars, 1899.

(5) Loew, U.S. Dep. of. Agric. Rep. No. 68, 1900.

(6) Pozzi-Escot, Bull. Soc. Cbim., Paris, 27 (iii) (1902), 280-288.

(7) Ville \& Moitessier, Bul. Soc. Cbim. 27 (iii) (1902), 1003.

(8) Senter, Z. f. Pbysikaliscbe Cbem. 44 (1903), 257-318.

(9) Wender, Cbem. Zeit. 26 (1903), 217.

(1о) A. Bach, Ber. 38 (1905), 1878-85.

(I I) Senter, Proc. Roy. Soc. 74 (1905), 201.

(12) Hans Euler, Cbem. Centr. (1905), (I), 941.

(13) van Laer, Bul. Soc. Cbim. Belg. (x-xii) XIX (1906).

(14) A. J. Brown, F. Cbem. Soc. 81 (1902), 373.

(15) E. F. Armstrong, Proc. Roy. Soc. 73 (1904), p. 500.

(16) Benjamin Moore, Article in Recent Advances in Pbysiology and Bio-Cbemistry, p. 86.

(17) Bayliss, Arch. des Sc. Biol. St. Petersburgb, XI, Supplement, 1904, p. 26 I.

(18) Brown, loc. cit.

(19) Armstrong, Proc. Roy. Soc. 73 (1904), p. 500.

(20) Bayliss, loc. cit.

(21) Armstrong and Caldwell, Proc. Roy. Soc. 74 (1904-5), p. 195.

(22) Schaffer, Am. Fourn. Physiol. XIV.

(23) Senter, Proc. Roy. Soc. 73 (1904.) 